\title{
Targeting the heme-oxidized nitric oxide receptor for selective vasodilatation of diseased blood vessels
}

\author{
Johannes-Peter Stasch, ${ }^{1}$ Peter M. Schmidt,, ${ }^{1,2}$ Pavel I. Nedvetsky, ${ }^{3}$ Tatiana Y. Nedvetskaya, ${ }^{3}$ \\ Arun Kumar H.S., ${ }^{3}$ Sabine Meurer, ${ }^{2,4}$ Martin Deile, ${ }^{3}$ Ashraf Taye, ${ }^{3}$ Andreas Knorr, ${ }^{1}$ \\ Harald Lapp, ${ }^{5}$ Helmut Müller, ${ }^{3}$ Yagmur Turgay, ${ }^{3}$ Christiane Rothkegel, ${ }^{1,6}$ Adrian Tersteegen, ${ }^{1}$ \\ Barbara Kemp-Harper, ${ }^{2,7}$ Werner Müller-Esterl, ${ }^{4}$ and Harald H.H.W. Schmidt',
}

\begin{abstract}
${ }^{1}$ Institute of Cardiovascular Research, Bayer HealthCare, Wuppertal, Germany. ${ }^{2}$ Department of Pharmacology, Monash University, Melbourne, Victoria, Australia. ${ }^{3}$ Rudolf-Buchheim-Institute for Pharmacology, Giessen, Germany. ${ }^{4}$ Institute for Biochemistry II, University of Frankfurt Medical School, Frankfurt, Germany. ${ }^{5}$ Helios Klinikum Erfurt, Erfurt, Germany. ${ }^{6}$ Martin-Luther-University, School of Pharmacy, Halle, Germany. ${ }^{7}$ Centre for Vascular Health, Monash University, Melbourne, Victoria, Australia.
\end{abstract}

\begin{abstract}
ROS are a risk factor of several cardiovascular disorders and interfere with $\mathrm{NO} /$ soluble guanylyl cyclase/ cyclic GMP (NO/sGC/cGMP) signaling through scavenging of $\mathrm{NO}$ and formation of the strong oxidant peroxynitrite. Increased oxidative stress affects the heme-containing NO receptor $\mathrm{sGC}$ by both decreasing its expression levels and impairing NO-induced activation, making vasodilator therapy with NO donors less effective. Here we show in vivo that oxidative stress and related vascular disease states, including human diabetes mellitus, led to an sGC that was indistinguishable from the in vitro oxidized/heme-free enzyme. This sGC variant represents what we believe to be a novel cGMP signaling entity that is unresponsive to NO and prone to degradation. Whereas high-affinity ligands for the unoccupied heme pocket of sGC such as zinc-protoporphyrin IX and the novel NO-independent sGC activator 4-[((4-carboxybutyl)\{2-[(4-pheneth ylbenzyl)oxy] phenethyl amino) methyl [benzoic] acid (BAY 58-2667) stabilized the enzyme, only the latter activated the NO-insensitive sGC variant. Importantly, in isolated cells, in blood vessels, and in vivo, BAY 58-2667 was more effective and potentiated under pathophysiological and oxidative stress conditions. This therapeutic principle preferentially dilates diseased versus normal blood vessels and may have far-reaching implications for the currently investigated clinical use of BAY 58-2667 as a unique diagnostic tool and highly innovative vascular therapy.
\end{abstract}

\section{Introduction}

Oxidative stress, a risk factor of several cardiovascular disorders, interferes with $\mathrm{NO} /$ cyclic GMP (NO/cGMP) signaling through scavenging of $\mathrm{NO}$ and formation of the strong intermediate oxidant peroxynitrite (ONOO-; refs. 1-4). Under these conditions, endothelial and vascular dysfunction develops, culminating in coronary heart disease, myocardial infarction, and stroke (5). Substituting NO with organic nitrates that release NO (NO donors) has been an important principle in cardiovas-

Nonstandard abbreviations used: BAY 41-2272, 5-cyclopropyl-2-[1-(2-fluoro-benzyl)-1H-pyrazolo[3,4-b]pyridin-3-yl]-pyrimidin-4-ylamine; BAY 58-2667, 4-[((4-carboxybutyl)\{2-[(4-phenethylbenzyl)oxy] phenethyl $\}$ amino) methyl [benzoic]acid; BNP, B-type natriuretic peptide; cGMP, cyclic GMP; DEA/NO, 2-( $N, N$-diethylamino)-diazenolate-2-oxide; $\mathrm{EC}_{50}, 50 \%$ effective concentration; $\mathrm{GTN}$, glycerol trinitrate; L-NAME, $\mathrm{N}$-nitro-L-arginine methylester; NAC, N-acetyl-cysteine; NZW, New Zealand (rabbits); ODQ, $1 \mathrm{H}-[1,2,4]$ oxadiazolo [3,4-a] quinoxalin-1-one; $\mathrm{ONOO}^{-}$, peroxynitrite; PDE, phosphodiesterase; PE, phenylephrine; PPIX, protoporphyrin IX; SIN-1, 3-morpholino-sydnonimine hydrochloride; sGC, soluble guanylyl cyclase; SHR, spontaneously hypertensive rats; TG(mRen2)27 rats, hypertensive transgenic renin rats; $\mathrm{U} 46619$, 9,11-dideoxy-9 $\alpha, 11 \alpha$-methanoepoxyprostaglandin F2 $\alpha$; WHHL, Watanabe heritable hyperlipidemic (rabbits)

Conflict of interest: Johannes-Peter Stasch and Andreas Knorr are currently full-time employees of Bayer HealthCare. Peter M. Schmidt was employed from 2000 to 2003 by Bayer HealthCare. Harald Lapp is the principal investigator of a clinical study of patients with acute decompensated heart failure using BAY 58-2667. Adrian Tersteegen is currently employed by Bayer HealthCare. Harald H.H.W. Schmidt is coinventor of a patent on the use of human sGC, owned by vasopharm $\mathrm{GmbH}$, and holds shares in that company.

Citation for this article: J. Clin. Invest. 116:2552-2561 (2006). doi:10.1172/JCI28371. cular therapy for more than a century. However, development of nitrate tolerance limits their continuous clinical application and, under oxidative stress and increased formation of $\mathrm{ONOO}^{-}$, foils the desired therapeutic effect (5). In addition, cardiovascular disease states are accompanied by downregulation of the activity and expression of the heme-containing NO receptor soluble guanylyl cyclase (sGC; refs. 6-8). In vitro, the activity of the NO-sensitive sGC can be directly impaired by $\mathrm{ONOO}^{-}$ $(9,10)$. Thus ROS both scavenge $\mathrm{NO}$ and, via $\mathrm{ONOO}^{-}$, inactivate its receptor with respect to NO sensing. One of the heterodimeric enzyme's redox-sensitive sites is a prosthetic heme group (11) bound to the smaller $(70-\mathrm{kDa}) \beta$ subunit; oxidation of its ferrous heme inhibits the NO-mediated activation of sGC (12). Possible further implications of heme oxidation in regulating enzyme stability and protein levels are not yet known; even whether oxidized sGC is present under (patho)physiological conditions is a matter of debate.

It would therefore be desirable to directly measure the intracellular molar ratio of $\mathrm{Fe}^{2+} / \mathrm{Fe}^{3+}$-containing and heme-free sGC, specifically against the background of all other cellular heme proteins with sufficient sensitivity and independent of artificially changing this ratio by the extraction procedure (see Supplemental Discussion; supplemental material available online with this article; doi:10.1172/JCI28371DS1). Such methods are not available to date. In lieu thereof, a recently discovered NOand heme-independent activator of sGC, 4-[((4-carboxybutyl) 


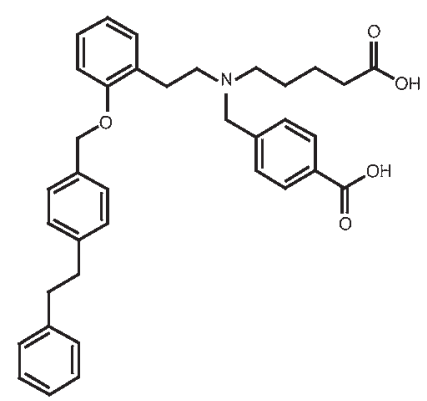

Figure 1

Chemical structure of BAY 58-2667.

\{2-[(4-phenethyl-benzyl)oxy] phenethyl\}amino)methyl[benzoic] acid (BAY 58-2667) appears to be the first experimental tool to assay the intracellular sGC redox state (13).

Stasch and coworkers have characterized BAY 58-2667 as an NO-independent sGC activator with unique pharmacological and biochemical properties such as potent in vitro and in vivo vasorelaxation even under conditions of nitrate tolerance and antiaggregatory activity not shared by nitrate-based sGC activators (13). Furthermore, BAY 58-2667 exhibited an unexpected biochemical feature, namely the activation of the oxidized/ heme-free state of sGC, indicating that this compound might be a valuable tool to access this "assumed-to-be" artificial redox state of sGC.

However, this initial work left major essential clinically and therapeutically relevant points open: Is oxidized/heme-free sGC just a biochemical artifact, or is it present under physiological conditions as part of a previously unrecognized sGC redox equilibrium? Are the effects of BAY 58-2667 due to the activation of oxidized or reduced sGC? Can this putative selectivity be exploited therapeutically in diseased versus normal blood vessels, and what are the long-term consequences of BAY 58-2667 in therapeutically relevant animal models? And, most important, is the compound active in normal and diseased human vessels?

\section{Figure 2}

Effects of competitive porphyrins and the $\mathrm{SGC} \mathrm{Fe} 2^{+/} / \mathrm{Fe}^{+}$redox ratio on BAY 58-2667 binding to and activation of sGC. (A) Human sGC activity in the presence of BAY 58-2667 (filled squares), PPIX (filled circles), $10 \mu \mathrm{M}$ BAY 58-2667 and various concentrations of PPIX (open squares), and $10 \mu \mathrm{M}$ PPIX and various concentrations of BAY 58-2667 (open circles). Basal activity was $17 \pm 3 \mathrm{nmol} / \mathrm{mg} / \mathrm{min}$. (B) Hemefree rat SGC activity in the presence of BAY 58-2667 (filled squares), PPIX (filled triangles), and $1 \mu \mathrm{M}$ BAY 58-2667 and various concentrations of PPIX (open circles). Basal activity was $90 \pm 7 \mathrm{nmol} / \mathrm{mg} / \mathrm{min}$. (C) Zn-PPIX (open squares), Fe ${ }^{2+}$-PPIX (filled circles), and Mn-PPIX (open circles) completely inhibited activation by $1 \mu \mathrm{M}$ BAY 58-2667 (filled squares) of heme-free rat sGC. (D) Zn-PPIX displaced ${ }^{3} \mathrm{H}-\mathrm{BAY}$ 58-2667 (100 nM) from heme-free rat sGC. (E) Rat sGC activity in the presence of DEA/NO (filled triangles), BAY 58-2667 (open squares), BAY 41-2272 (filled circles), and BAY 41-2272 combined with $10 \mathrm{nM} D E A / N O$ (open circles). (F) Rat SGC activity in the presence of $100 \mathrm{nM}$ BAY 58-2667 (filled circles) combined with increasing concentrations of ODQ. Open triangles represent controls. (G) Binding of $100 \mathrm{nM}{ }^{3} \mathrm{H}-\mathrm{BAY} 58-2667$ to $\mathrm{sGC}$ in the presence of increasing concentrations of ODQ. (H-J) Same conditions as $\mathbf{E}-\mathbf{G}$ but with heme-free rat SGC. Data are means \pm SEM of 3-6 independent experiments performed in triplicate.
In the present work we therefore aimed to go beyond the initial characterization of BAY 58-2667 and to address these clinically relevant questions. We demonstrate for the first time to our knowledge that BAY 58-2667 selectively activates a state of sGC that is indistinguishable from the NO-insensitive oxidized/heme-free state of the enzyme, introducing to vascular medicine what we believe to be a novel mode of sGC activation and vasodilatation. We demonstrate that ROS such as $\mathrm{ONOO}^{-}$, a hallmark of various cardiovascular diseases, are capable of shifting the sGC redox equilibrium to the ferric NO-insensitive state. BAY 58-2667 could represent the first therapeutic principle that preferentially targets diseased blood vessels, which we have shown here in vitro and in vivo including in human vascular disease models, known to be accompanied by increased levels of vascular oxidative stress. Collectively, we hereby extend the initial discovery and observations of BAY 58-2667 to what we believe to be a new concept of vascular dysfunction and suggest a therapeutic approach to this via an enzyme- and redox-specific drug.
A

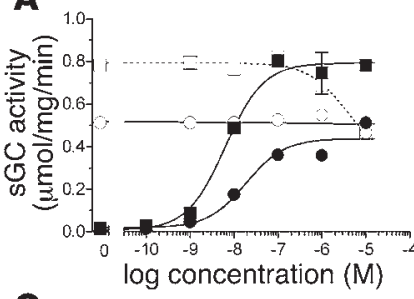

C

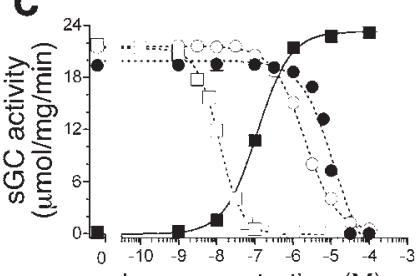

log concentration (M)

E

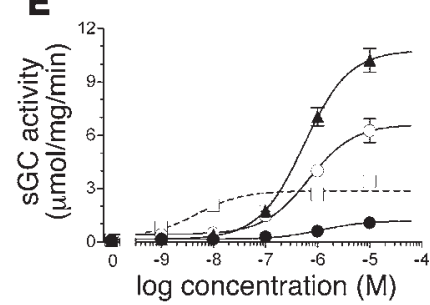

G
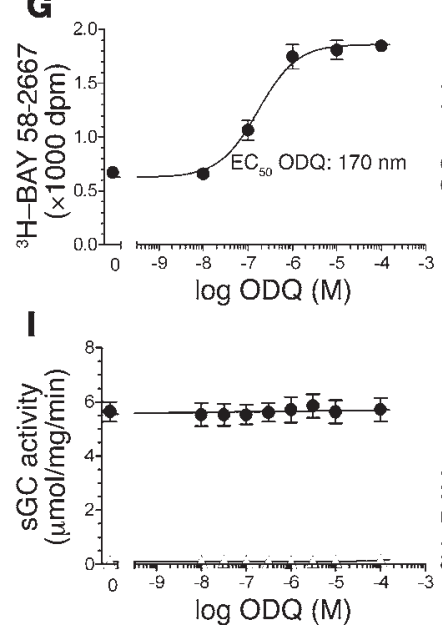
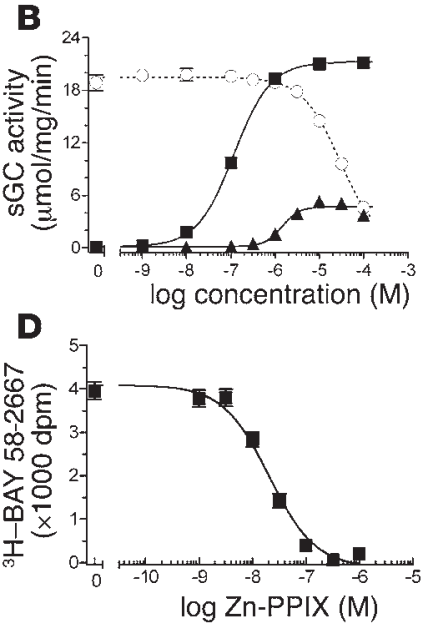

F

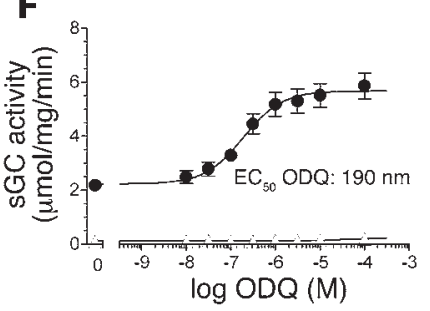

H

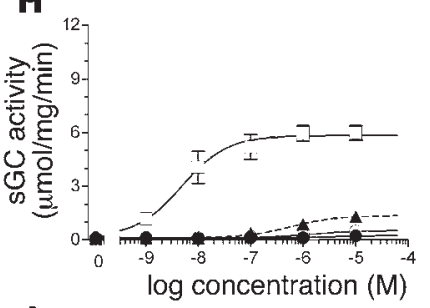

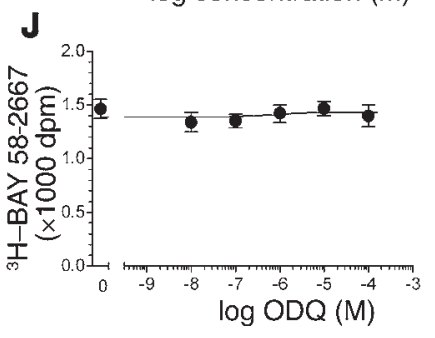



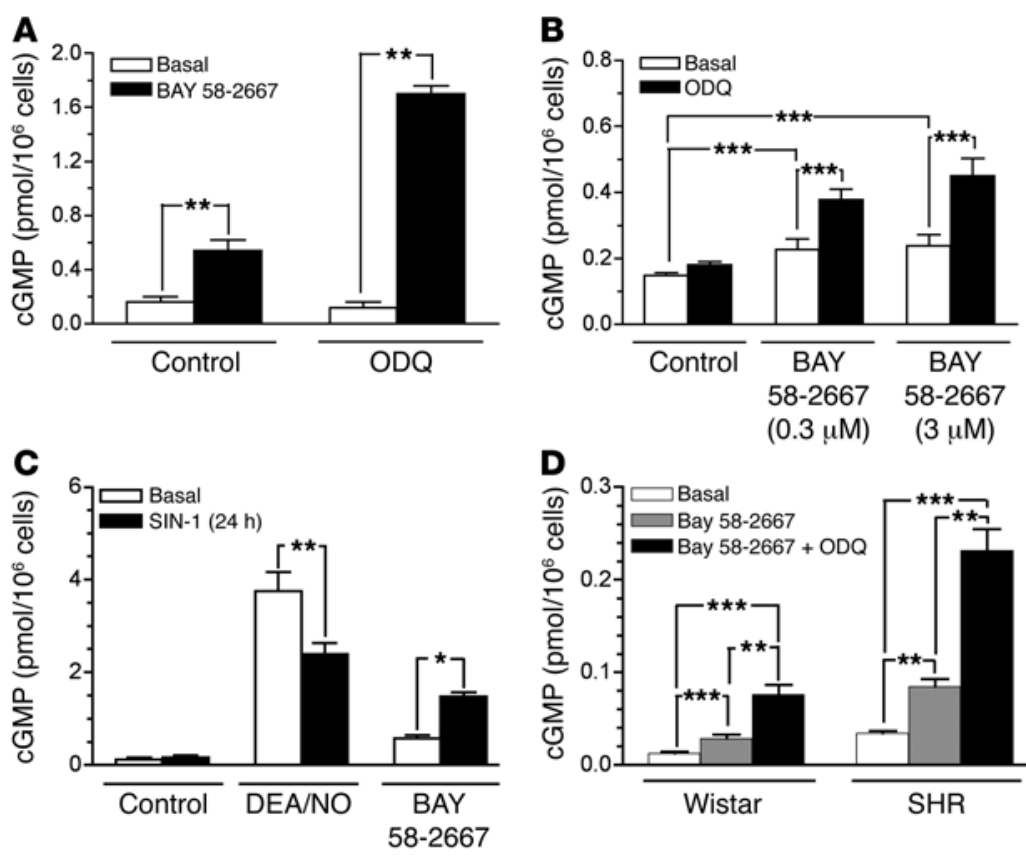

\section{Figure 3}

Effects of oxidative agents on BAY 58-2667-induced cGMP accumulation in native cells. (A) Basal (white bars) and BAY 58-2667-stimulated (black bars) cGMP accumulation were measured in untreated (control) porcine pulmonary artery endothelial cells and cells treated for 30 minutes with $20 \mu \mathrm{M}$ ODQ. (B) Basal and BAY 58-2667-stimulated cGMP accumulation was measured in untreated (white bars) human platelets and human platelets treated with ODQ for 30 minutes (black bars). Basal cGMP level was $0.15 \pm 0.01 \mathrm{pmol} / 10^{6} \mathrm{cells}$. (C) Basal, $250 \mu \mathrm{M} \mathrm{DEA} / \mathrm{NO}-$ stimulated, and $10 \mu \mathrm{M}$ BAY 58-2667-stimulated cGMP accumulation was measured in untreated (white bars) endothelial cells and cells treated with $500 \mu \mathrm{M} \mathrm{SIN-1}$ for 24 hours (black bars). Basal cGMP level was $0.16 \pm 0.04 \mathrm{pmol} / 10^{6}$ cells. Data are means \pm SEM of 3 independent experiments performed in triplicate. (D) cGMP content of aortic rings of Wistar rats and SHR (5-6 months of age) exposed to vehicle (white bars), $10 \mu \mathrm{M}$ BAY 58-2667 (gray bars), or $10 \mu \mathrm{M}$ BAY 58-2667 plus $10 \mu \mathrm{M}$ ODQ (black bars). cGMP levels are expressed as mean \pm SEM of $5-10$ animals. ${ }^{*} P<0.05$; ${ }^{\star *} P<0.01 ;{ }^{* \star} P<0.001$.

\section{Results}

To establish BAY 58-2667 (Figure 1) as an adequate tool to follow changes in the intracellular sGC redox equilibrium, we first aimed to clarify in vitro whether oxidized rather than reduced sGC is the primary target of sGC activators that are known to bind to the sGC heme pocket, e.g., BAY 58-2667 and protoporphyrin IX (PPIX).

The majority of a standard recombinant sGC preparation will be purified in a reduced heme-containing state; however, like for any other purified heme protein, small amounts of oxidized and heme-free enzyme will also be present in virtually unpredictable ratios. Stimulation of such a preparation with the NO donor 2-(N,N-diethylamino)-diazenolate-2-oxide (DEA/NO; $300 \mu \mathrm{M})$ and PPIX $(10 \mu \mathrm{M})$ produced a 23 - and 32 -fold stimulation of cGMP formation compared with basal enzymatic activity, respectively (data not shown). Similar to PPIX, BAY 58-2667 activated sGC in a concentration-dependent manner from $0.1 \mathrm{nM}$ to $10 \mu \mathrm{M}$ (Figure 2A); however, BAY 58-2667 was more potent and effective than PPIX (50\% effective concentration [EC 50 ], BAY 58-2667, $6.4 \pm 0.68 \mathrm{nM}$; versus PPIX, $18.7 \pm 5.24 \mathrm{nM} ; P<0.05)$. When both compounds were coincubated, a maximally activating concentration of PPIX prevented further activation by BAY 58-2667 (Figure 2A). Similar results were obtained with a preparation of exclusively heme-free recombinant sGC (Figure $2 \mathrm{~B}$ ), indicating that BAY 58-2667 and PPIX compete for the same subpopulation and binding site of heme-free sGC within this enzyme preparation. This view was further supported by the observed competition between BAY 58-2667 and non-sGC-activating metalloporphyrins: BAY 58-2667-stimulated sGC activity was blocked by Zn-, Mn-, and $\mathrm{Fe}^{2+}$-protoporphyrin in a competitive manner (Figure 2C). Moreover, in a radioligand binding study, sGC-bound, ${ }^{3} \mathrm{H}$-labeled BAY 58-2667 was completely replaced by Zn-PPIX (Figure 2D; $\mathrm{IC}_{50}$, $20 \pm 1.3 \mathrm{nM}$ ). This result strongly suggests that BAY 58-2667 and PPIX activate heme-free sGC by binding to the unoccupied heme pocket. Pharmacologically, PPIX behaved as a partial agonist, BAY 58-2667 as a full agonist, and Zn-PPIX as a competitive antagonist at the sGC heme pocket.
In addition to its effect on the heme-free sGC, BAY 58-2667 also activated the heme-containing, oxidized enzyme. To address the effect of the $\mathrm{Fe}^{2+} / \mathrm{Fe}^{3+}$ sGC redox ratio on the BAY 58-2667 response, heme-containing and heme-free sGC were incubated with increasing concentrations of $1 \mathrm{H}-[1,2,4]$ oxadiazolo [3,4-a]quinoxalin-1-one (ODQ) in the presence of BAY 58-2667. Upon exposure to DEA/NO, BAY 58-2667, and 5-cyclopropyl-2-[1-(2-fluoro-benzyl)-1H-pyrazolo[3,4b]pyridin-3-yl]-pyrimidin-4-ylamine (BAY 41-2272), native sGC showed the activation profile of a heme-containing enzyme (Figure 2E). In the presence of a maximally activating concentration of $100 \mathrm{nM}$ BAY 58-2667, sGC activity was further enhanced by ODQ ( $\mathrm{EC}_{50}, \sim 190 \mathrm{nM}$; Figure $\left.2 \mathrm{~F}\right)$. This concentration-dependent effect of ODQ was consistent with binding studies showing an ODQ-dependent increase in ${ }^{3} \mathrm{H}-\mathrm{BAY} 58-2667$ binding with a similar $\mathrm{EC}_{50}(\sim 170 \mathrm{nM}$; Figure $2 \mathrm{G})$. The excellent correlation of these findings supports the notion that ODQ or other oxidizing mechanisms shift the redox equilibrium to oxidized, BAY 58-2667-sensitive form. A mechanism by which BAY 58-2667 discriminates between both sGC redox states was suggested earlier: BAY 58-2667, although a nonporphyrinic structure, is able to mimic the spatial structure of the heme, allowing direct competition of both ligands for the sGC heme-binding pocket (14). However, only the weakly bound oxidized heme (15) can be effectively replaced by BAY 58-2667. In contrast, no competition with the reduced heme was observed, even at concentrations at the limit of solubility of BAY 58-2667, foiling any classical receptor-binding approach (16). Consistently, at the heme-free enzyme BAY 58-2667-induced sGC activation and binding quickly reached saturation that was not influenced by further addition of ODQ (Figure 2, I and J). DEA/NO alone or combined with the NO sensitizer BAY 41-2272 showed no sGC activation (Figure $2 \mathrm{H}$ ). These data establish in vitro that BAY 58-2667 activates only the heme-deficient enzyme via a direct interaction with the unoccupied heme-binding pocket or by displacing the weakly bound, oxidized heme. 
A

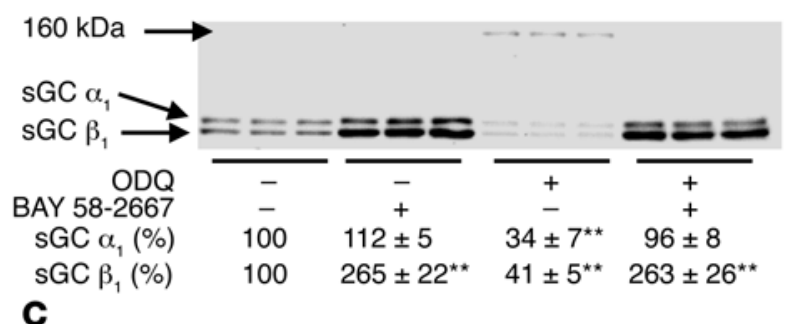

C

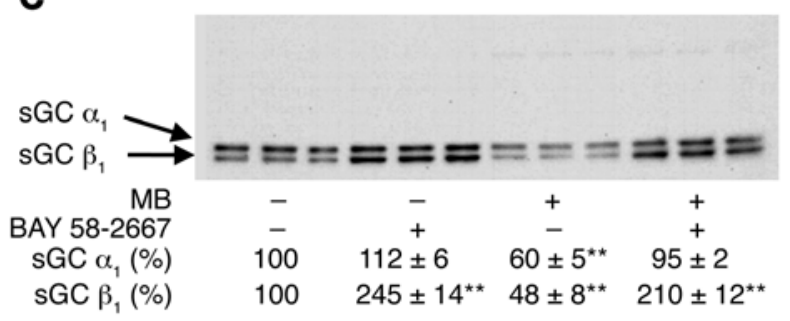

E

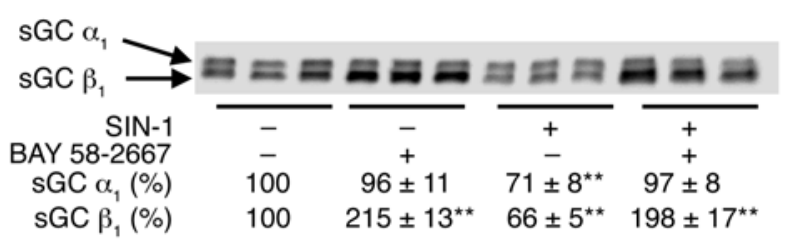

G

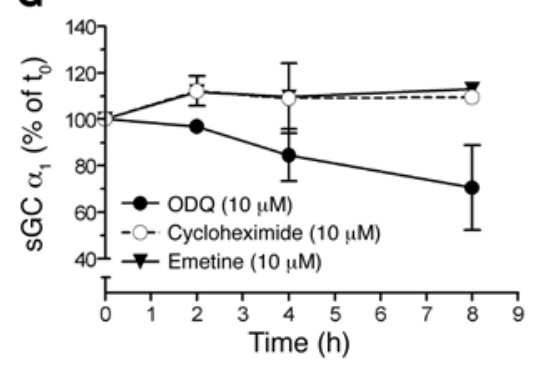

H

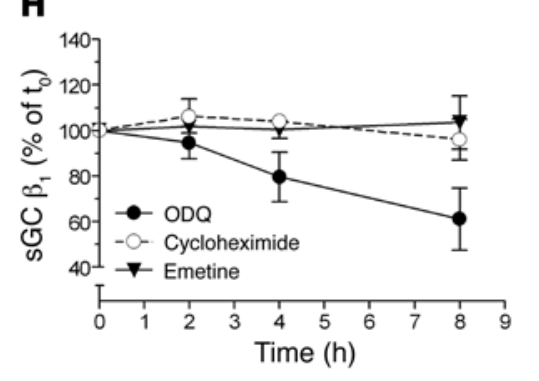

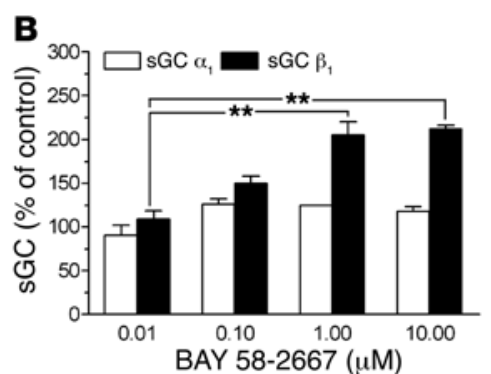

D
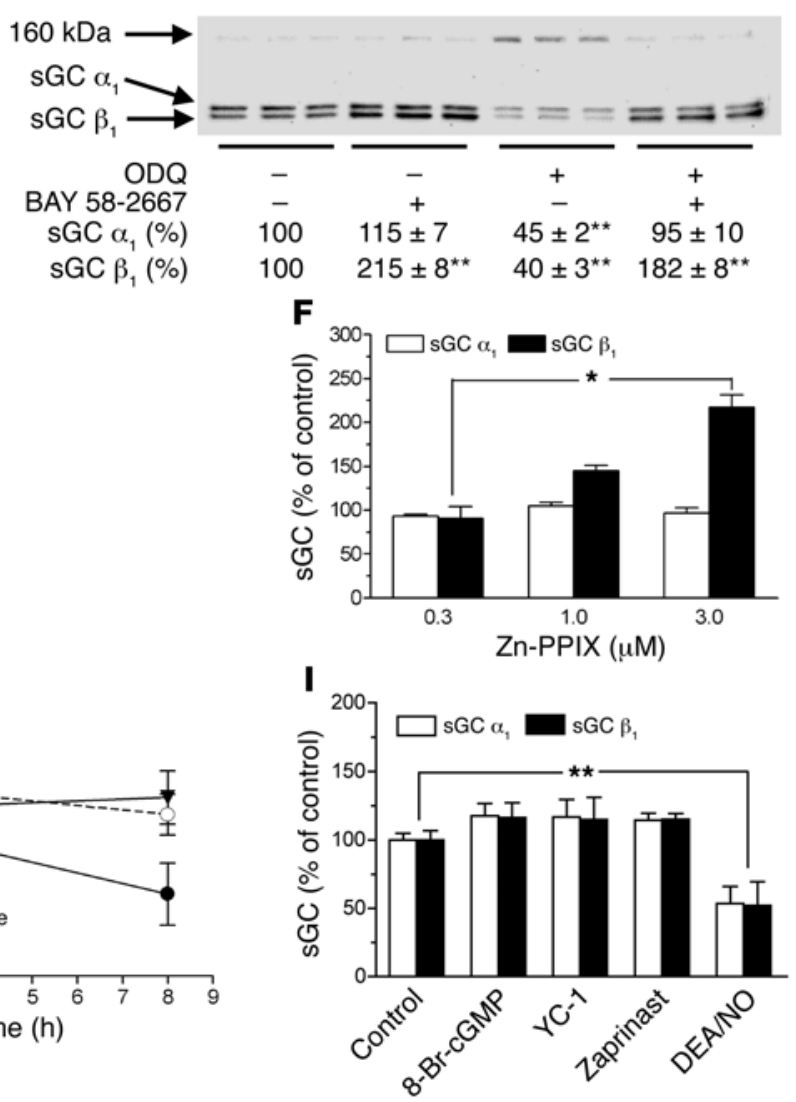

Figure 4

Effects of BAY 58-2667 on sGC protein levels under normal and oxidative conditions. (A) Endothelial cells were incubated for 24 hours with $10 \mu \mathrm{M}$ ODQ, $10 \mu$ M BAY 58-2667, or the combination of both compounds. (B) Endothelial cells were treated with different concentrations of BAY 58-2667 for 24 hours. (C) Endothelial cells were incubated for 24 hours with $10 \mu \mathrm{M}$ methylene blue (MB), $10 \mu \mathrm{M}$ BAY 58-2667, or the combination of both compounds. (D) Porcine smooth muscle cells were incubated for 24 hours with $10 \mu \mathrm{M}$ ODQ, $10 \mu \mathrm{M}$ BAY 58-2667, or the combination of both compounds. (E) Endothelial cells were incubated for 24 hours with $500 \mu \mathrm{M} \mathrm{SIN-1,} 10 \mu \mathrm{M}$ BAY 58-2667, or the combination of both compounds. (F) Endothelial cells were treated with different concentrations of Zn-PPIX for 48 hours. (G) sGC $\alpha$ and (H) sGC $\beta$ protein expression in endothelial cells preincubated with $10 \mu \mathrm{M}$ ODQ, $10 \mu \mathrm{g} / \mathrm{ml}$ cycloheximide, or $10 \mu \mathrm{g} / \mathrm{ml}$ emetine for 0, 2, 4, and 8 hours. (I) Endothelial cells were treated for 24 hours with $250 \mu \mathrm{M}$ 8-Br-cGMP, $100 \mu \mathrm{M}$ YC-1, $200 \mu \mathrm{M}$ of the PDE inhibitor Zaprinast, and $100 \mu \mathrm{M}$ DEA/NO. All sGC protein levels were determined by Western blot. Data are expressed as percent of control (means \pm SEM of 3-6 independent experiments performed in triplicate). ${ }^{\star} P<0.05 ;{ }^{\star \star} P<0.01$. On $\mathbf{A}, \mathbf{C}, \mathbf{D}$, and $\mathbf{E}$, representative blots are shown.

Next we addressed whether a BAY 58-2667-sensitive sGC is present in native endothelial cells. Exposure of endothelial cells to BAY 58-2667 (10 $\mu \mathrm{M}, 3$ minutes) produced a small but significant 3.4-fold increase in cGMP levels that was increased to 10 -fold upon pretreatment with ODQ $(20 \mu \mathrm{M}, 30$ minutes; Figure 3A). Similar results were obtained in human platelets (Figure 3B). BAY 58-2667 had virtually no effect on a broad range of cyclic nucleotide-metabolizing enzymes (phosphodies- terase [PDE] inhibition by $10 \mu \mathrm{M}$ BAY 58-2667 for PDE1, $1 \%$; for PDE2, 5\%; for PDE3, 4\%; for PDE4, 2\%; for PDE5, 1\%; for PDE6, $15 \%$; for PDE7, 2\%; for PDE8, -4\%; for PDE9, 0\%; for PDE11, 4\%), indicating that increased cGMP accumulation must be due to an effect on cGMP synthesis rather than cGMP degradation. To investigate whether the effectiveness of BAY 58-2667 to stimulate oxidized sGC in intact cells holds true for models of oxidative stress that resemble more vascular disease conditions, we 
A
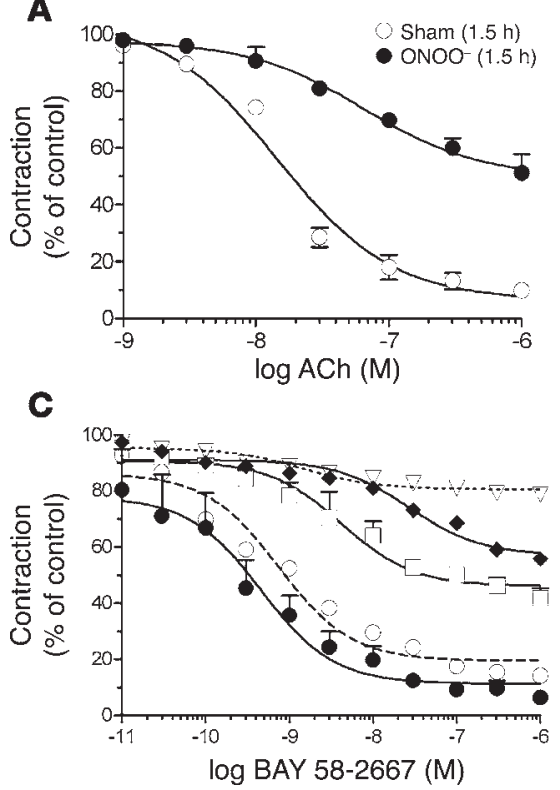

B

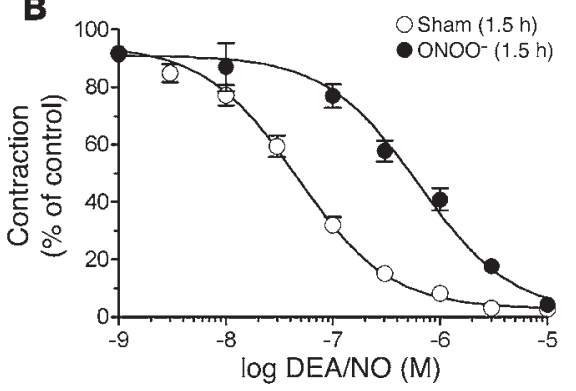

D

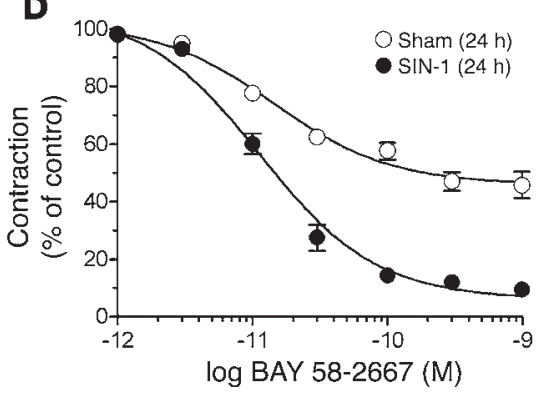

Figure 5

Effects of ONOO- or the ONOO- donor, SIN-1, on relaxation of rat thoracic aorta. Vessels were incubated in with and without $\mathrm{ONOO}^{-}(1 \mathrm{mM}$ lumazine, $58 \mu / \mathrm{IXO}, 200 \mu \mathrm{M}$ SPER-NO) and/or 1-10 mM NAC for 1.5 hours or $100 \mu \mathrm{M} \mathrm{SIN-1}$ for 24 hours. Thereafter, relaxation in responses to $(\mathbf{A})$ acetylcholine (ACh), (B) DEA/NO, or (C and D) BAY 58-2667 were measured. (C) $1 \mathrm{mM}$ (filled diamonds) and $10 \mathrm{mM}$ (open triangles) NAC, ONOO- (filled circles), and 10 mM NAC plus ONOO- (open circles) were compared to a 1.5-hour sham incubation (open squares). Data are presented as means \pm SEM of 4 (acetylcholine), 6 (DEA/NO), or 9 (BAY 58-2667) independent experiments performed in duplicate. used the $\mathrm{ONOO}^{-}$donor 3-morpholino-sydnonimine hydrochloride (SIN-1; ref. 17). $\mathrm{ONOO}^{-}$, generated by the reaction between superoxide and $\mathrm{NO}$, was shown to decrease NO-stimulated sGC activity $(9,10)$, and heme oxidation was suggested to be a possible mechanism for this effect (7). Indeed, when endothelial cells were treated with $500 \mu \mathrm{M}$ SIN-1 for 24 hours, a significant decrease in NO donor-stimulated cGMP accumulation was observed while the BAY 58-2667 response increased (Figure 3C). In agreement with the above findings obtained with the purified enzyme (Figure 2, C and D), Zn-PPIX (10 $\mu \mathrm{M})$ selectively abolished the BAY 58-2667-induced increase in cellular cGMP while the NO response remained unaffected (data not shown). Together, these data demonstrate under physiological and more so under oxidative stress the intracellular occurrence of a BAY 58-2667-sensitive sGC that is indistinguishable from the isolated heme-free and/or oxidized enzyme.

Besides these acute effects of BAY 58-2667 on sGC activity, we observed a second chronic effect: prolonged exposure of endothelial cells to BAY 58-2667 resulted in an additional increase in the protein levels of the heme-binding sGC $\beta_{1}$ subunit (Figure 4B), while NO donors, NO sensitizers of sGC like YC-1, or cGMP analogs had no significant effect - or the opposite effect - on sGC protein levels (Figure 4I). We hypothesize that this effect of BAY 58-2667 is based on reduced degradation due to stabilization of the sGC $\beta$ subunit upon BAY 58-2667 binding to its heme pocket. While the importance of sGC heme and its redox state for the regulation of enzyme activity is well understood, its role in regulating sGC stability and protein levels is unclear. Conflicting data regarding the effects of oxidation on sGC protein levels have been reported. ODQ prevents the NOinduced decrease of sGC protein levels in smooth muscle cells (18), whereas treatment of chromaffin cells with ODQ results in a loss of sGC protein (19). In good agreement with these latter data, we found a decrease in $\mathrm{SGC}$ protein levels upon exposing porcine endothelial (Figure 4A) or smooth muscle cells (Figure 4D) to ODQ. Mechanistically, the effect of ODQ on sGC protein is most likely due to ubiquitin-dependent protein degradation
(Supplemental Figures 2 and 3). The ODQ-induced decrease in $\mathrm{sGC}$ protein was faster than by inhibiting protein synthesis (cycloheximide or emetine; Figure 4, G and H). Another substance known to oxidize sGC heme, methylene blue (20-22), also decreased sGC protein levels (Figure 4C). Importantly, the effects of all tested heme oxidants - ODQ, SIN-1 (Figure 4E), and methylene blue - on sGC protein levels were completely prevented in the presence of BAY 58-2667. These data suggest that oxidation of sGC heme results not only in the loss of NOsensitive sGC activity but also in ubiquitin-dependent sGC protein degradation (Supplemental Figures 2 and 3).

The latter mechanism apparently involves a reduced affinity of the apo-enzyme for the oxidized heme and possible loss of the prosthetic heme group (14), which is why heme mimetics that occupy the heme binding pocket, stabilize the enzyme and consequently increase steady-state levels of sGC protein. To determine whether the stabilization of sGC is a unique feature of BAY 58-2667 or whether it is a general property of ligands to the sGC $\beta_{1}$ hemebinding pocket, we examined the effects of $\mathrm{Zn}$-PPIX, which has high affinity for sGC ( $K_{\mathrm{d}}, 16 \mathrm{nM}$; ref. 23). Zn-PPIX also increased sGC $\beta_{1}$ protein levels without affecting sGC $\alpha_{1}$ levels, similar to the effects of BAY 58-2667 (Figure 4F).

While other interpretations of these data cannot be excluded, a likely explanation is that occupation of the heme-binding site with high-affinity heme mimetics in general prevents oxidation-induced, ubiquitin-dependent sGC degradation. The sGC $\alpha$ subunit is unable to bind heme, making this subunit insensitive to heme oxidants but also to stabilizing heme-site ligands. The $\alpha$ subunit is, however, affected indirectly by the oxidationinduced decrease of the $\beta$ protein levels, as sGC is only stable as a heterodimer and single sGC subunits are prone to degradation (24). This explains why the protein levels of both subunits decreased in parallel upon addition of different heme oxidants. Once high-affinity heme-site ligands such as BAY 58-2667 or $\mathrm{Zn}$-PPIX were added, the sGC $\beta$ subunit was stabilized, resulting in the observed strong increase in this protein's expression. The availability of the stabilized $\beta$ subunit conserves the sGC 
A

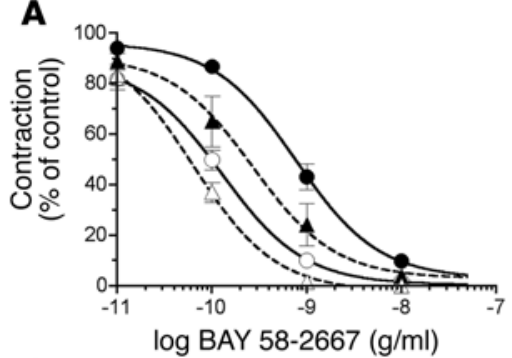

c

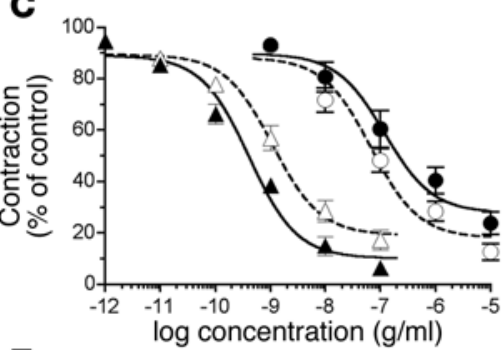

E

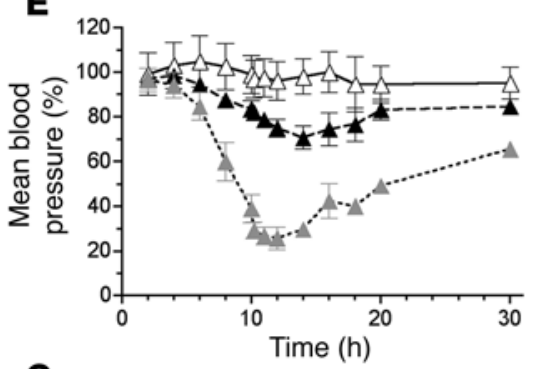

G

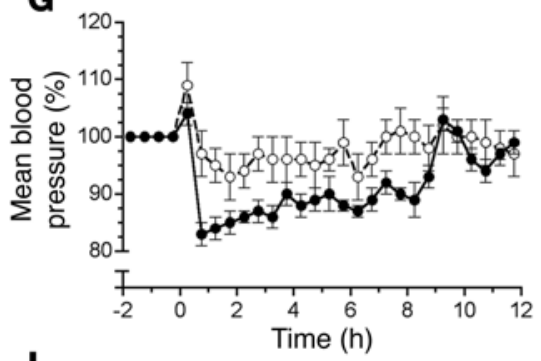

B

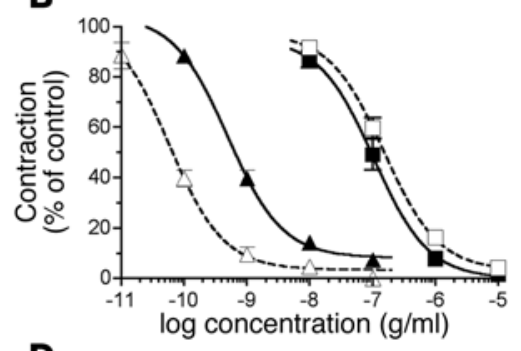

D

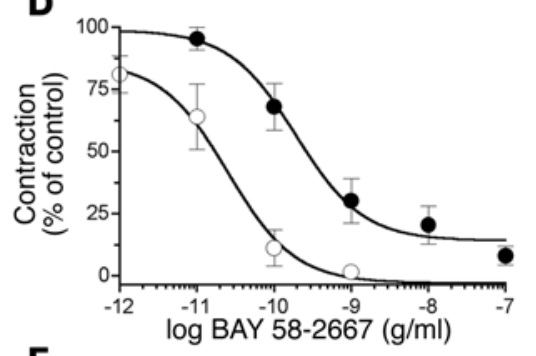

$\mathbf{F}$

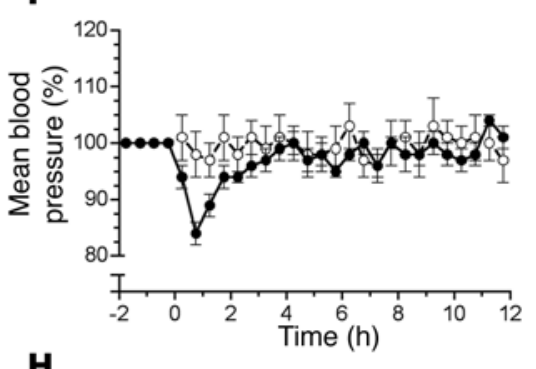

H

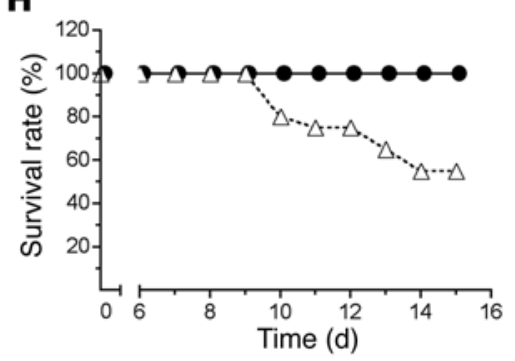

\section{Figure 6}

Vasorelaxing effects of BAY 58-2667 in vitro and in vivo. (A) BAY 58-2667-induced relaxation of PE precontracted aorta from Wistar rats (circles) and aged SHR (triangles) with (open symbols) and without (filled symbols) ODQ. (B) BAY 58-2667- (triangles) or SNP-induced (squares) inhibition of PE precontracted saphenous arteries from NZW (filled symbols) and WHHL rabbits (open symbols). (C) BAY 58-2667- (triangles) or GTN-induced (circles) inhibition of U46619 precontracted aorta from $\mathrm{ApoE}^{-/-}$ mice on normal (open symbols) or high-fat diet (filled symbols). (D) BAY 58-2667-induced inhibition of PE precontracted human mesocolon arteries from patients with (open circles) and without (filled circles) type 2 diabetes. Means \pm SEM of $6-12$ vessels shown in A-D. (E) Effect of i.v. BAY 58-2667 $(10 \mu \mathrm{g} / \mathrm{kg})$ with (gray triangles) and without (filled triangles) ODQ pretreatment (2 mg/kg i.v., 10 minutes before BAY 58-2667) or vehicle (open circle) on MAP in anesthetized rats $(n=4)$. Baseline was $117 \pm 3$ to $128 \pm 4 \mathrm{mmHg}$. (F) Effect of oral BAY 58-2667 (filled circles, $3.0 \mathrm{mg} / \mathrm{kg}$ ) and vehicle (open circles) on MAP in conscious Wistar rats. Baseline was $106 \pm 4$ and $102 \pm 3 \mathrm{mmHg}$ (control versus treated, respectively; $n=6$ ). (G) Effect of oral BAY 58-2667 (filled circles, $3.0 \mathrm{mg} / \mathrm{kg}$ ) and vehicle (open circles) on MAP in conscious SHR. Baseline was $135 \pm 11$ and $133 \pm 4 \mathrm{mmHg}$ (control versus treated, respectively; $n=6$ ). In $\mathbf{E}-\mathbf{G}$, predrug values of each group were normalized to $100 \%$. (H) Survival rate in BAY 58-2667-treated (filled circles, $3 \mathrm{mg} / \mathrm{kg}$ orally twice daily) and untreated (open triangles) TGR(mRen2)27 under L-NAME. (I) Plasma levels of BNP, renin, creatinine, and urea in BAY 58-2667-treated (black bars) versus control animals (white bars). Values are means \pm SEM. ${ }^{* * *} P<0.001$.

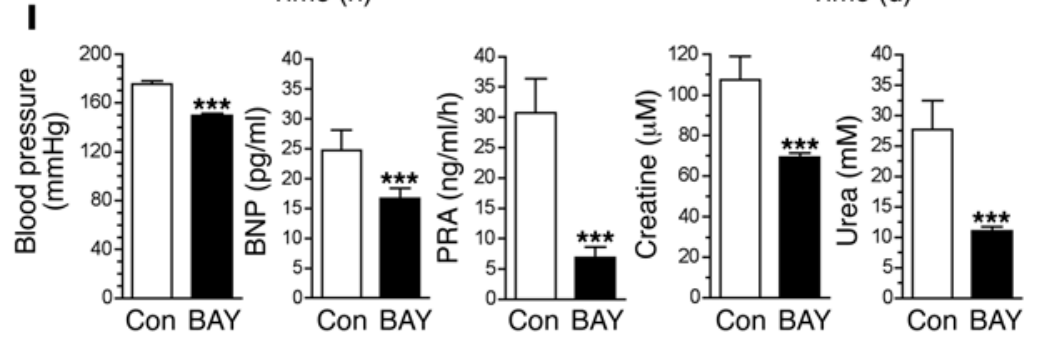

$\alpha$ protein on the level of controls as stable heterodimers can be formed. However, as the $\alpha$ subunit cannot bind heme or other heme-site ligands, its physiological turnover is not affected, explaining the lack of increased $\alpha$ protein levels as observed for the $\beta$ subunit. These data indicate that under oxidizing conditions, BAY 58-2667 and Zn-PPIX preserve stable heterodimeric sGC levels in an active (BAY 58-2667) or inactive ( $\mathrm{Zn}$-PPIX) state and, in addition, result in the accumulation of nonfunctional $\beta$ mono- or probably homodimers (25).

Moreover, our data indicate that BAY 58-2667 may represent a unique vasodilator that is of particular use under conditions of oxidative stress. Therefore, we extended our experiments to functionally analyze isolated blood vessels. Rat aortic ring preparations were incubated with and without the endogenous oxidant $\mathrm{ONOO}^{-}$for 1.5 hours or with SIN-1 for 24 hours, and the relaxation of phenylephrine (PE) precontraction was measured in response to acetylcholine, DEA/NO, or BAY 58-2667. Contractility of the vessels was not affected by the long-term treatment with SIN-1 (data not shown). However, the maximal relaxation in response to acetylcholine was impaired $\left(\mathrm{ONOO}^{-}\right.$, $48.8 \% \pm 6.6 \%$; versus control, $90.3 \% \pm 1.4 \%$; Figure $5 \mathrm{~A})$. The NO donor DEA/NO produced complete relaxation of both control 


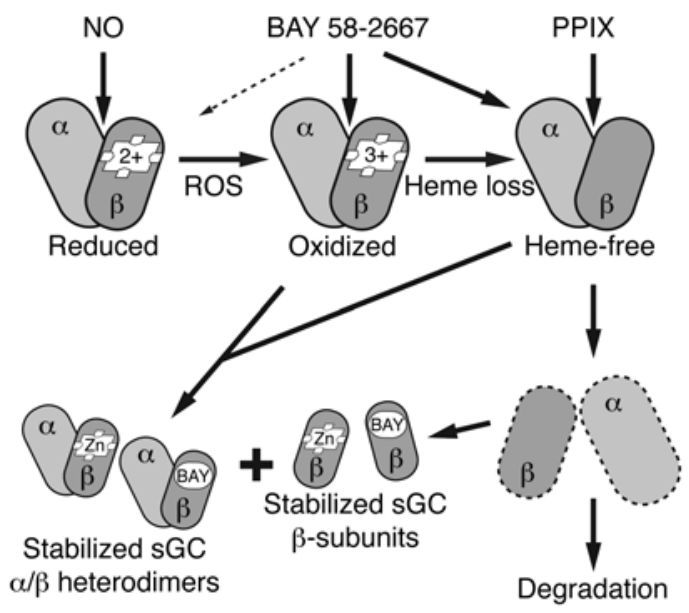

Figure 7

NO receptor SGC exists in a physiological equilibrium between 2 redox states, the reduced and NO-sensitive versus the oxidized and heme mimetic-sensitive form. Under pathophysiological conditions, this relative ratio is shifted toward the oxidized form, which is selectively targeted by sGC activators such as BAY 58-2667 to overcome the pathophysiology of impaired NO-cGMP signaling. In addition, high-affinity heme-site ligands such as Zn-PPIX (Zn) or BAY 58-2667 (BAY) are able to block the oxidation-accelerated degradation of the $s G C \alpha / \beta$ heterodimer, thereby stabilizing and conserving the enzyme protein levels in an inactive (Zn-PPIX-bound) or active (BAY 58-2667-bound) form even under oxidizing conditions. Furthermore, heme-site ligands decelerate the physiological turnover of the $\mathrm{sGC} \beta$ subunit, resulting in an accumulation of this monomeric protein.

and $\mathrm{ONOO}^{-}$-treated vessels, but its potency was decreased 10fold after treatment with $\mathrm{ONOO}^{-}\left(\mathrm{EC}_{50}, \mathrm{ONOO}^{-}, 6.20 \pm 0.24\right.$ $\log \mathrm{M}$; versus control, $7.34 \pm 0.04 \log \mathrm{M}$; Figure $5 \mathrm{~B})$. In contrast, the sensitivity to BAY 58-2667 was increased after treatment with both $\mathrm{ONOO}^{-}\left(\mathrm{EC}_{50}, \mathrm{ONOO}^{-}, 9.34 \pm 0.11 \log \mathrm{M}\right.$; versus control, $8.27 \pm 0.05 \log$; Figure $5 \mathrm{C}$ ) and SIN-1 (EC 50 , SIN-1, $11.35 \pm 0.06 \log$; versus control, $10.64 \pm 0.05 \log \mathrm{M}$, Figure 5D). Moreover, following 1.5 hours of treatment with $\mathrm{ONOO}^{-}$ (Figure 5C) and 24 hours of treatment with SIN-1 (Figure 5D), the increase in the maximum response to BAY 58-2667 was striking. Consistently, pretreatment with the reductant $\mathrm{N}$-acetyl-cysteine (NAC) dramatically lowered the effectiveness of BAY 58-2667 (Figure 5C). Thus the vasorelaxant potency and efficacy of BAY 58-2667 is increased under conditions of oxidative stress.

To validate this unprecedented feature of a vasodilator drug, we investigated vascular reactivity in 4 distinct disease models involving endogenous oxidative stress rather than exogenously induced oxidative stress: aged spontaneously hypertensive rats (SHR), Watanabe heritable hyperlipidemic (WHHL) rabbits, $A p o E^{-/-}$mice on high-fat diet, and human mesocolon arteries from patients with type 2 diabetes.

BAY 58-2667 inhibited the PE-induced contraction of aortic rings from normal and aged SHR in a concentration-dependent manner $\left(\mathrm{IC}_{50}\right.$, normal SHR, $1.23 \pm 0.16 \mathrm{nM}$; aged SHR, $0.35 \pm 0.14 \mathrm{nM}$; $P<0.01)$, and the addition of ODQ $(10 \mu \mathrm{M})$ shifted the concentration-response curves leftward $\left(\mathrm{IC}_{50}\right.$, normal SHR, $0.15 \pm 0.03 \mathrm{nM}$; aged SHR, $0.09 \pm 0.013 \mathrm{nM} ; P<0.01$; Figure $6 \mathrm{~A})$. These results show that BAY 58-2667 more potently relaxes vessels from hypertensive rats than normotensive rats if the heme group of $\mathrm{sGC}$ is oxidized. To validate that this enhanced vasorelaxation was indeed mediated by sGC stimulation, we measured the effects of BAY 58-2667 on vascular cGMP levels in aortas taken from normal rats and SHR with and without $10 \mu \mathrm{M}$ ODQ pretreatment. Figure 3D shows that exposure of $10 \mu \mathrm{M}$ BAY 58-2667 induced significantly higher cGMP levels in aortas from hypertensive versus normotensive rats and that this cGMP increase was further potentiated in the presence of ODQ.

In WHHL rabbits a marked attenuation of the endotheliumdependent vasodilatation has been identified as a characteristic of early stages of atherosclerosis related to enhanced inactivation of endothelium-derived NO by superoxide (26). BAY 58-2667 inhibited PE-induced contractions of saphenous artery rings from WHHL rabbits more potently than of control New Zealand (NZW) rabbits ( $\mathrm{IC}_{50}$, WHHL, $0.1 \pm 0.012 \mathrm{nM}$; NZW, $1.2 \pm 0.09 \mathrm{nM} ; P<0.001)$. However, the NO donor sodium nitroprusside relaxed precontracted arteries from WHHL and NZW rabbits with no significant difference ( IC $_{50}$, NZW, $105 \pm 24 \mathrm{nM}$; WHHL, $153 \pm 25$ nM; Figure 6B).

To confirm these data in a third animal model for vascular disease, we investigated the vasorelaxing effects of BAY 58-2667 and the NO donor glycerol trinitrate (GTN) on precontracted aortas from $A p o E^{-/-}$mice fed standard and high-fat diets. BAY 58-2667 inhibited precontracted vessels ( $\mathrm{IC}_{50}$, standard diet, $4.0 \pm 0.28 \mathrm{nM}$; high-fat diet, $0.7 \pm 0.09 \mathrm{nM} ; P<0.001$; Figure $6 \mathrm{C})$. In contrast, the relaxation response to GTN was impaired in $A p o E^{-/-}$mice on the high-fat diet $\left(\mathrm{IC}_{50}\right.$, standard diet, $67.5 \pm 20.8 \mathrm{nM}$; high-fat diet, $119 \pm 54.3 \mathrm{nM} ; P<0.01)$. These data suggest that a milder degree of sGC oxidation occurs physiologically and that accumulated oxidized sGC under pathophysiological conditions represents a pool that can be selectively stimulated by BAY 58-2667 to cause selective vasodilatation of pathological blood vessels.

We then sought to apply these observations to human tissue. Since diminished activity of vascular sGC has also been reported in animal models of type 2 diabetes (27), we investigated the relaxing effect of BAY 58-2667 in human arteries taken from human mesocolon specimens obtained during bypass surgery from patients with and without type 2 diabetes. Indeed, BAY 58-2667 relaxed arteries from diabetic patients more potently than controls $\left(\mathrm{IC}_{50}, 0.03 \pm 0.002 \mathrm{nM}\right.$; versus control, $0.39 \pm 0.02 \mathrm{nM} ; P<0.001$; Figure 6D). Thus selective targeting of heme-oxidized sGC extends to human forms of oxidative stress and vascular disease.

Finally, we wanted to investigate the effectiveness and selectivity of BAY 58-2667 at the in vivo level with and without ODQ pretreatment. In anesthetized rats, BAY 58-2667 produced a dose-dependent and long-lasting hypotension (Figure 6E). After i.v. administration of $10 \mu \mathrm{g} / \mathrm{kg}$ BAY 58-2667, a maximal effect of $29 \mathrm{mmHg}$ was observed. Pretreatment with ODQ induced not only a significant increase in effectiveness to $71 \mathrm{mmHg}$, but it also prolonged the effect's duration (Figure 6E). Upon oral administration of $3 \mathrm{mg} / \mathrm{kg}$ BAY 58-2667, the hypotension lasted longer in conscious SHR than in normotensive Wistar rats (Figure 6, F and G). Given that chronic inhibition of NO synthesis in rats increases aortic superoxide anion production via an activated renin angiotensin system (28), the cardiovascular consequences of sGC activation were evaluated by the long-term effects of BAY 58-2667 in hypertensive transgenic renin rats $[\mathrm{TG}(\mathrm{mRen} 2) 27$ rats] treated with the NOS inhibitor N-nitro-L-arginine methylester (L-NAME). Systolic blood pressure, as measured by the tail cuff method, increased in 11-week-old TG(mRen2)27 rats that received L-NAME from 
$159 \pm 3 \mathrm{mmHg}$ to $176 \pm 3 \mathrm{mmHg}$, whereas in animals treated with BAY $58-2667$ the systolic pressure decreased slightly to $150 \pm 3 \mathrm{mmHg}$ (Figure $6 \mathrm{H}$ ). At the end of the study, plasma B-type natriuretic peptide (BNP), creatinine, urea, and renin activity were significantly lower, reflecting cardiorenal protection effect (Figure 6I). Most notably, the overall beneficial effect of BAY 58-2667 was reflected in a significant reduction in mortality. During the course of study, 9 of 20 control animals died, whereas in the treatment group all 15 animals stayed alive.

\section{Discussion}

Murad, Furchgott, and Ignarro originally outlined the endogenous NO-cGMP signaling pathway in blood vessels. Since then, different ligands and stimulators ranging from small molecular compounds to proteins have also been shown to stimulate heme-containing sGC in the cardiovascular system. In 2002, we described a member of a novel structural class of compounds (BAY 58-2667) that, in contrast to the NO-independent but heme-dependent sGC stimulators such as YC-1, BAY 41-2272, and BAY 41-8543, could activate sGC in its NO-insensitive, oxidized (or heme-deficient) state (13). The activation of this presumably artificial state of sGC was an unexpected biochemical feature and not fully recognized as a drug target. Here we provide compelling evidence that an sGC that is indistinguishable from oxidized/heme-free sGC occurs physiologically and can be selectively targeted by BAY 58-2667. Most important, the levels of oxidized/heme-free sGC appear to increase in various pathophysiological animal models and in human cardiovascular diseases that are accompanied by increased production of ROS, suggesting a causal link among vascular dysfunction, ROS formation, heme oxidation, and ultimately heme loss. The selectivity of BAY 58-2667 for oxidized/heme-free sGC thus allows for targeting of diseased blood vessels in an unprecedented manner and with potency in the low $\mathrm{nM}$ range.

In order to validate BAY 58-2667 as a potent tool for identifying oxidized/heme-free sGC in vitro and in vivo, we established BAY 58-2667 as a full agonist at the heme-binding site of sGC, PPIX as a partial agonist, and $\mathrm{Zn}$-PPIX as a full antagonist. The fact that $\mathrm{Zn}$-PPIX lowers cGMP levels in vivo suggests that endogenous ligands for heme-free sGC exist.

Here we describe what we believe to be a new signaling pathway prevalent under disease conditions. Moreover, we observed that oxidized sGC seems to be prone to accelerated degradation through ubiquitinilation. BAY 58-2667 stabilizes heme-free sGC in a positive feedback loop. This selective vasodilation may in the future also be used as a functional diagnostic tool in humans. Potential therapeutic indications may include heart failure, hypertension, pulmonary hypertension, renal failure, and peripheral arterial occlusive disease.

In summary, our data indicate that sGC exists under physiological conditions in an equilibrium between its reduced and oxidized state; oxidative stress shifts this ratio more to the NO-insensitive ferric/heme-free form (Figure 7). The selectivity of BAY 58-2667 to activate this oxidation-impaired/heme-free form of sGC has important implications for the pharmacology of sGC, the fundamental understanding of $\mathrm{sGC}$ regulation in $\mathrm{NO}$ signaling, and the potential use of BAY 58-2667 as a diagnostic tool and as a highly innovative therapy for vascular disease; for the first time to our knowledge, selective vasodilatation of diseased blood vessels under oxidative stress is possible.

\section{Methods}

BAY 58-2667 was synthesized as described previously (29) at a purity of 98.6\% as determined by HPLC, NMR, and liquid chromatography mass spectroscopy. The compound may be obtained from Bayer HealthCare via a material transfer agreement. BAY 41-2272, DEA/NO, and ODQ were purchased from Alexis Biochemicals; Axxora. All other chemicals of analytical grade were obtained from Sigma-Aldrich.

Purification of $s G C$ and activity assay. Recombinant human and rat sGC was expressed using the Sf9/baculovirus system and purified as described previously $(3,25,30)$. Measurement of human recombinant sGC activity with subsequent determination of cGMP content by enzyme immunoassay was performed as described previously (31). Activity of recombinant rat sGC was measured by formation of [ $\left.{ }^{32} \mathrm{P}\right]$-cGMP from $\left[\alpha-{ }^{32} \mathrm{P}\right]-\mathrm{GTP}(30)$. Removal of the sGC heme moiety and subsequent removal of the detergent was performed as described previously (30).

Cell culture. Porcine pulmonary artery endothelial cell culture was performed as described previously (32). Smooth muscle cells were isolated enzymatically by incubation of the aortic inner surface with collagenase type CLS II $(0.5 \mathrm{mg} / \mathrm{ml}, 10 \mathrm{~min}$ at room temperature) after removal of endothelial cells. Growth media used were M199 for endothelial cells and DMEM (Sigma-Aldrich) for smooth muscle cells, both supplemented with $10 \%$ fetal calf serum, $100 \mathrm{U} / \mathrm{ml}$ penicillin, and $100 \mu \mathrm{g} / \mathrm{ml}$ streptomycin. Passages 6-8 (for smooth muscle cells) or confluent cell monolayers from the second passage (for endothelial cells) were used for experiments. To measure intracellular cGMP content, cells were stimulated with the compounds indicated in Figures 3 and 4, medium was removed, and $70 \%$ ethanol was added. After evaporation of ethanol, cells were homogenized in assay buffer (BIOTREND), and cGMP was measured by enzyme immunoassay according to the manufacturer's instructions. Alternatively, for Western blot analysis, cells were lysed in $250 \mu \mathrm{l}$ Roti-Load (Carl Roth) sample buffer preheated to $95^{\circ} \mathrm{C}$ and then boiled for an additional 10 minutes.

Aortic cGMP. Determination of vascular cGMP content of rat aortic rings was performed as described previously (33).

Human platelets. Isolation of human platelets and cGMP measurements were performed as described previously (13).

Western blotting. Immunodetection of sGC proteins was performed as described previously (31). Detection of sGC $\alpha_{1} / \beta_{1}$ was performed using subunit-specific antibodies (31). Quantification of luminescent signals was performed using Kodak Imager Station 440CF.

Receptor binding study. Binding studies were performed as described previously (16).

$P D E$ inhibition. The preparation of PDE isoenzymes and inhibition of PDE enzyme activity have been previously described (34).

Human vessels. We included consecutive patients scheduled for elective bowel surgery if they fulfilled the following inclusion criteria: aged 50-75 years, no risk factors for atherosclerosis or diabetes or at least 2 risk factors for atherosclerosis and type 2 diabetes of at least 2 years' duration, and written informed consent. Patients were excluded if 1 or more of the following criteria were fulfilled: age less than 50 or greater than 75 years, type 1 diabetes, or vasodilator therapy during surgery. The medical history of patients eligible for the study was recorded using a standardized questionnaire that contained the following items: type of surgery and anesthesia, additional diseases and/or events, standard laboratory parameters, and regular medication. Vessels with a diameter of 1.5-2.5 mm were dissected from the mesocolon, and segments of $2.0 \mathrm{~cm}$ were gently isolated from fat and loose connective tissue. The preparations were immediately collected into vials with chilled modified Krebs Henseleit buffer and immediately transferred for experiments. The study was carried out in adherence to the Declaration of 
Helsinki and approved by the ethics committee of the University of Witten/Herdecke (no. 82/2004).

Vasorelaxation studies. Rat thoracic aortas and human vessels were rapidly isolated, and vessels were prepared as described previously $(26,35)$. After isolation, vessels were transferred into Krebs buffer containing additional $2 \%$ fetal calf serum, $100 \mathrm{U} / \mathrm{ml}$ penicillin, and $100 \mu \mathrm{g} / \mathrm{ml} \mathrm{strep-}$ tomycin. Vessels were incubated in this solution for 24 hours at $37^{\circ} \mathrm{C}$ under an atmosphere of $5 \% \mathrm{CO}_{2}$ and saturated humidity. After mounting, vessels were allowed to equilibrate for 90 minutes before addition of any drugs. Krebs buffer was renewed every 15 minutes throughout the experimental protocol, except during the generation of concentration-response curves. After the normalization procedure, vessels were contracted with a high-potassium solution $(80 \mathrm{mM} \mathrm{KCl})$ to determine whether they were viable. After precontraction of the vessels with PE $(60-80 \%$ of maximum) until they reached a stable contraction plateau, cumulative concentration-dependent relaxation to acetylcholine, DEA/ NO, GTN, or BAY 58-2667 was assessed.

Vasorelaxing measurements on saphenous arteries from rabbits at the age of about 1.5 years (about $2-3 \mathrm{~kg}$, male NZW rabbits, E.S.D. Romans Elevage Scientifique des Dombes; male WHHL rabbits, CRP: WHHL Covance Research Products) were performed as previously described (13).

Male ApoE $E^{-/-}$mice at 6-8 weeks of age were fed a normal diet or a westerntype diet ( $21 \%$ raw fat, $0.15 \%$ cholesterol, 19.5 casein; Ssniff) for 16 weeks. Agematched C57BL/6J mice fed a normal diet were used as wild-type controls. Animals were killed by decapitation under general anesthesia and aortas were isolated $(1.5 \mathrm{~mm})$ and suspended immediately under an initial tension of approximately $0.5 \mathrm{~g}$ in $5 \mathrm{ml}$ organ bath containing Krebs-Henseleit solution (118 mM NaCl, $4.7 \mathrm{mM} \mathrm{KCl}, 2.5 \mathrm{mM} \mathrm{CaCl}_{2}, 1.2 \mathrm{mM} \mathrm{MgSO}_{4}, 1.2 \mathrm{mM}$ $\mathrm{KH}_{2} \mathrm{PO}_{4}, 25 \mathrm{mM} \mathrm{NaHCO} 3,5.5 \mathrm{mM}$ D-glucose, and $25 \mu \mathrm{M}$ EDTA-Ca-salt, $\mathrm{pH} 7.4$ ) at $37^{\circ} \mathrm{C}$. Contractions were measured isometrically with Statham UC2 strain gauges connected to a DASI802HC data acquisition board (Keithley). Rings were precontracted by potassium chloride (100 nM) 3 times. Each contraction was followed by a series of 16 washing cycles and a resting period of 28 minutes. The aortic rings were subsequently contracted with the thromboxane analog 9,11-dideoxy- $9 \alpha, 11 \alpha$-methanoepoxyprostaglandin F2 $\alpha$ (U46619; maximal concentration, $3 \times 10^{-9} \mathrm{~g} / \mathrm{ml}$ ). When the contractile response reached a plateau, the test compound was cumulatively added to the bath solution. The relaxation responses obtained were expressed as a percentage of the maximal contraction evoked by U46619.

Hemodynamics in anesthetized rats. Measurements were performed as previously described (13). Vehicle or ODQ was applied 10 minutes before BAY $58-2667$ administration in a volume of $0.1 \mathrm{ml} / \mathrm{kg}$. Both compounds were administered i.v. in a solution of Transcutol/Cremophor EL/physiological saline $(10: 10: 80 \mathrm{vol} / \mathrm{vol} / \mathrm{vol})$ in a volume of $1 \mathrm{ml} / \mathrm{kg}$.

Twenty-four-hour blood pressure measurements in conscious SHR and Wistar rats. Measurements were performed as previously described (13).

Long-term in vivo study. Eleven-week-old TGR(mRen2)27 rats were randomized in 2 groups, a control group and a group treated with BAY 58-2667. Rats of both groups were given L-NAME in their drinking water $(500 \mathrm{mg} / \mathrm{l})$; rats of the treatment group additionally received $10 \mathrm{mg} / \mathrm{kg}$ BAY 58-2667 orally twice daily for 5 weeks, whereas the control group received no treatment. The substance was administered as a suspension in Transcutol/Cremophor EL/water (10:20:70 vol/vol/vol) by gavage. Systolic blood pressure was measured weekly by the tail-cuff method. Blood samples were taken at the end of the study and collected after decapitation into chilled tubes containing EDTA. BNP was determined after extraction using $\mathrm{C}_{18}$-cartridges (Bond Elut; Varian Inc.) with a radioimmunoassay kit (BIOTREND). Plasma renin activity was determined by measurement of angiotensin I accumulated in the plasma samples during incubation for 1 hour at $37^{\circ} \mathrm{C}, \mathrm{pH} 6.0$, and was measured using a commercial radioimmunoassay kit (Sorin Biomedia).

Statistics. Data are reported as means \pm SEM. Differences were assessed by 1-way repeated-measures ANOVA followed by Bonferroni test for comparison of means. Statistical comparisons of $\mathrm{IC}_{50}$ values were performed by paired Student's $t$ test. All statistical calculations were performed using GraphPad Prism 3.0 software (GraphPad Software).

\section{Acknowledgments}

This study was supported by grants from Deutsche Forschungsgemeinschaft (SFB547/C7 and C10) and the National Health \& Medical Research Council and the National Heart Foundation, Australia. P.M. Schmidt is the recipient of an Alexander-von-Humboldt Lynen fellowship.

Received for publication March 1, 2006, and accepted in revised form July 11, 2006.

Address correspondence to: Harald H.H.W. Schmidt or Peter M. Schmidt, Monash University, School of Biomedical Sciences, Department of Pharmacology Wellington Road, Melbourne, Clayton, Victoria 3800, Australia. Phone: 61-3-9905-5752; Fax: 61-3-9905-5729; E-mail: Harald.Schmidt@med.monash.edu.au (H.H.H.W. Schmidt). Phone: 61-3-990-20218; Fax: 61-3-990-55851; E-mail: Peter.Schmidt@med.monash.edu.au (P.M. Schmidt).
1. Hare, J.M. 2004. Nitroso-redox balance in the cardiovascular system. N. Engl. J. Med. 351:2112-2114.

2. Harrison, D.G. 1997. Endothelial function and oxidant stress. Clin. Cardiol. 20:II-11-17.

3. Melichar, V.O., et al. 2004. Reduced cGMP signaling associated with neointimal proliferation and vascular dysfunction in late-stage atherosclerosis. Proc. Natl. Acad. Sci. U. S. A. 101:16671-16676.

4. Pryor, W.A., and Squadrito, G.L. 1995. The chemistry of peroxynitrite: a product from the reaction of nitric oxide with superoxide. Am. J. Physiol. 268:L699-L722.

5. Warnholtz, A., et al. 2002. Adverse effects of nitroglycerin treatment on endothelial function, vascular nitrotyrosine levels and cGMP-dependent protein kinase activity in hyperlipidemic Watanabe rabbits. J. Am. Coll. Cardiol. 40:1356-1363.

6. Bauersachs, J., et al. 1998. Vasodilator dysfunction in aged spontaneously hypertensive rats: changes in NO synthase III and soluble guanylyl cyclase expression, and in superoxide anion production. Cardiovasc. Res. 37:772-779.
7. Kloss, S., Bouloumie, A., and Mulsch, A. 2000. Aging and chronic hypertension decrease expression of rat aortic soluble guanylyl cyclase. Hypertension. 35:43-47.

8. Ruetten, H., Zabel, U., Linz, W., and Schmidt, H.H 1999. Downregulation of soluble guanylyl cyclase in young and aging spontaneously hypertensive rats. Circ. Res. 85:534-541.

9. Mulsch, A., et al. 2001. Effects of in vivo nitroglycerin treatment on activity and expression of the guanylyl cyclase and cGMP-dependent protein kinase and their downstream target vasodilatorstimulated phosphoprotein in aorta. Circulation. 103:2188-2194.

10. Weber, M., Lauer, N., Mulsch, A., and Kojda, G. 2001. The effect of peroxynitrite on the catalytic activity of soluble guanylyl cyclase. Free Radic. Biol. Med. 31:1360-1367.

11. Ignarro, L.J., Degnan, J.N., Baricos, W.H., Kadowitz, P.J., and Wolin, M.S. 1982. Activation of purified guanylate cyclase by nitric oxide requires heme. Comparison of heme-deficient, heme-reconstitut- ed and heme-containing forms of soluble enzyme from bovine lung. Biochim. Biophys. Acta. 718:49-59.

12. Schrammel, A., Behrends, S., Schmidt, K., Koesling, D., and Mayer, B. 1996. Characterization of $1 \mathrm{H}-[1,2,4]$ oxadiazolo[4,3-a]quinoxalin-1-one as a heme-site inhibitor of nitric oxide-sensitive guanylyl cyclase. Mol. Pharmacol. 50:1-5.

13. Stasch, J.P., et al. 2002. NO- and haem-independent activation of soluble guanylyl cyclase: molecular basis and cardiovascular implications of a new pharmacological principle. Br. J. Pharmacol. 136:773-783.

14. Schmidt, P.M., Schramm, M., Schroder, H., Wunder, F., and Stasch, J.P. 2004. Identification of residues crucially involved in the binding of the heme moiety of soluble guanylate cyclase. J. Biol. Chem. 279:3025-3032.

15. Hobbs, A.J. 2000. Soluble guanylate cyclase [review]. Expert Opin. Ther. Targets. 4:735-749.

16. Schmidt, P., Schramm, M., Schroder, H., and Stasch, J.P. 2003. Receptor binding assay for nitric oxide- and heme-independent activators of soluble 
guanylate cyclase. Anal. Biochem. 314:162-165.

17. Darley-Usmar, V.M., Hogg, N., O'Leary, V.J., Wilson, M.T., and Moncada, S. 1992. The simultaneous generation of superoxide and nitric oxide can initiate lipid peroxidation in human low density lipoprotein. Free Radic. Res. Commun. 17:9-20.

18. Filippov, G., Bloch, D.B., and Bloch, K.D. 1997. Nitric oxide decreases stability of mRNAs encoding soluble guanylate cyclase subunits in rat pulmonary artery smooth muscle cells. J. Clin. Invest. 100:942-948.

19. Ferrero, R., and Torres, M. 2002. Prolonged exposure of chromaffin cells to nitric oxide down-regulates the activity of soluble guanylyl cyclase and corresponding mRNA and protein levels. $B M C$ Biochem. 3:26.

20. Luo, D., Das, S., and Vincent, S.R. 1995. Effects of methylene blue and LY83583 on neuronal nitric oxide synthase and NADPH-diaphorase. Eur. J. Pharmacol. 290:247-251.

21. Mayer, B., Brunner, F., and Schmidt, K. 1993. Novel actions of methylene blue. Eur. Heart J. 14(Suppl. I):22-26.

22. Mayer, B., Brunner, F., and Schmidt, K. 1993. Inhibition of nitric oxide synthesis by methylene blue. Biochem. Pharmacol. 45:367-374.

23. Serfass, L., and Burstyn, J.N. 1998. Effect of heme oxygenase inhibitors on soluble guanylyl cyclase activity. Arch. Biochem. Biophys. 359:8-16.

24. Mergia, E., Friebe, A., Dangel, O., Russwurm, M., and Koesling, D. 2006. Spare guanylyl cyclase NO receptors ensure high $\mathrm{NO}$ sensitivity in the vascular system. J. Clin. Invest. 116:1731-1737. doi:10.1172/ JCI27657.

25. Zabel, U., Hausler, C., Weeger, M., and Schmidt, H.H.H.W. 1999. Homodimerization of soluble guanylyl cyclase subunits. Dimerization analysis using a glutathione s-transferase affinity tag. J. Biol. Chem. 274:18149-18152.

26. Warnholtz, A., et al. 1999. Increased NADH-oxidase-mediated superoxide production in the early stages of atherosclerosis: evidence for involvement of the renin-angiotensin system. Circulation. 99:2027-2033.

27. Witte, K., et al. 2002. Dysfunction of soluble guanylyl cyclase in aorta and kidney of Goto-Kakizaki rats: influence of age and diabetic state. Nitric oxide. 6:85-95.

28. Kitamoto, S., et al. 2000. Chronic inhibition of nitric oxide synthesis in rats increases aortic superoxide anion production via the action of angiotensin II. J. Hypertens. 18:1795-1800.

29. Alonso-Alija, C., et al. 2001. Novel derivatives of dicarboxylic acid having pharmaceutical properties.
World Intellectual Property Organization patent WO/2001/019780, filed August 31, 2000, and issued March 22, 2001. http://www.wipo.int/ pctdb/en/wo.jsp?KEY=01/19780.010907.

30. Hoenicka, M., et al. 1999. Purified soluble guanylyl cyclase expressed in a baculovirus/Sf9 system: stimulation by YC-1, nitric oxide, and carbon monoxide. J. Mol. Med. 77:14-23.

31. Nedvetsky, P.I., Kleinschnitz, C., and Schmidt, H.H.H.W. 2002. Regional distribution of protein and activity of the nitric oxide receptor, soluble guanylyl cyclase, in rat brain suggests multiple mechanisms of regulation. Brain Res. 950:148-154.

32. Zabel, U., et al. 2002. Calcium-dependent membrane association sensitizes soluble guanylyl cyclase to nitric oxide. Nat. Cell Biol. 4:307-311.

33. Priviero, F.B., et al. 2005. Mechanisms underlying relaxation of rabbit aorta by BAY 41-2272, a nitric oxide-independent soluble guanylate cyclase activator. Clin. Exp. Pharmacol. Physiol. 32:728-734.

35. Wunder, F., et al. 2005. Characterization of the first potent and selective PDE9 inhibitor using a cGMP reporter cell line. Mol. Pharmacol. 68:1775-1781.

34. Arun, K.H., Kaul, C.L., and Ramarao, P. 2005. AT1 receptors and L-type calcium channels: functional coupling in supersensitivity to angiotensin II in diabetic rats. Cardiovasc. Res. 65:374-386. 